\title{
Characterization of Tympanic Cavity Volume in Newborns using Computerized Tomography Scanning
}

\author{
Caracterización del Volumen de la Cavidad Timpánica en \\ Recién Nacidos usando Tomografía Computadorizada
}

\begin{abstract}
Niyazi Acer"; Erdogan Unur*; M. Fatih Sönmez**; Gökmen Zararsız***; Ayla Arslan*; Ayse Sagıroglu*; Tolga Ertekin"; Mustafa Erkan ${ }^{* * * * *}$; Abdulhakim Coskun ${ }^{* * * * *}$ \& Mehmet Bilgen ${ }^{* * * * * *}$
\end{abstract}

ACER, N.; UNUR, E.; SÖNMEZ, M. F.; ZARARSIZ, G.; ARSLAN, A.; SAGIROGLU, A.; ERTEKIN, T.; ERKAN, M.; COSKUN, A. \& BILGEN, M. Characterization of tympanic cavity volume in newborns using computerized tomography scanning. Int. J. Morphol., 34(1):189-196, 2016.

SUMMARY: This study reports tympanic cavity (TC) volume in newborns, which was missing in the literature. Ex vivo histology and computerized tomography (CT) scans were performed on temporal bone and data were analyzed in part using software developed in house. CT images with a slice thickness of $0.5 \mathrm{~mm}$ were obtained from 5 newborn cadavers and analyzed independently by two expert researchers. The border of the TC was delineated manually and measurement of area of interest was calculated on masked images. Then, the area measurements from all sections were added to estimate the total volume. The agreements between the histological and CT findings were then compared for accuracy, repeatability and reliability. The Dice and Jaccard similarity coefficient measures were used as a statistical validation metric to evaluate the assessor's performance in manual volume segmentation. Good assessor agreement was observed with average Dice values above 0.8 indicating that consistent and reliable volume measurements were feasible. The proposed protocol was shown to be accurate in calculating the TC volume, and thus can be used for computer-assisted presurgical planning or for diagnosing structural alterations in TC.

KEY WORDS: Computerized tomography; Tympanic cavity; Tympanic cavity volume; Similarity index.

\section{INTRODUCTION}

Tympanic cavity (TC) is an important but highly complicated anatomical structure within the temporal bone of the middle ear. It includes proper and epitympanic recess. The former component is located opposite to tympanic membrane and the later one is positioned above it and covers the upper half of malleus and the greater part of incus (Standring, 2008). Typically, TC volume does not vary between left and right sides or with gender, but increases with age (Kavakli et al., 2004; Kürkçüoglu et al., 2010; Ikui et al., 2000).

Diseases related to middle ear are highly prevalent in pediatric population. An anatomical abnormality, such as perforation of tympanic membrane can cause hearing loss in children. Middle ear volume is interesting because it correlates with otitis. Also, hearing loss is increased by smaller volume caused by a drum perforation or a problem with the ossicular transmission (Mehta et al., 2006). In clinics, visualization of TC and measurement of its volume are used as critical diagnostic markers for assessing the origin of the loss. In addition, such information also aids treatment planning or surgical intervention of such cases. So far, however, there are no reports documenting the TC volume or its expected normative size in newborns. Therefore, this study was initiated to fill this gap relevant to the pediatric anatomy in literature.

In the first part of the study, histological analysis was performed on specimens extracted from 5 pediatric cadavers, and provided a gold standard for the TC volume in newborns.

\footnotetext{
Department of Anatomy, Medical Faculty, Erciyes University, Kayseri, Turkey.

** Department of Histology-Embryology, Medical Faculty, Erciyes University, Kayseri, Turkey.

*** Department of Biostatistics, Medical Faculty, Erciyes University, Kayseri, Turkey.

**** Department of Otolaryngology, Medical Faculty, Erciyes University, Kayseri, Turkey.

***:** Department of Pediatric Radiology, Medical Faculty, Erciyes University, Kayseri, Turkey.

******* Department of Biophysics, Medical Faculty, Adnan Menderes University, Aydin, Turkey.
} 
Evaluation of temporal bone in clinically relevant fashion in patients would require radiological imaging. Computerized tomography (CT) and magnetic resonance imaging (MRI) are the two common techniques used for reference imaging of temporal bone or its related structures. CT currently offers images with higher resolution than MRI, but its use in pediatric population was avoided since the operation requires ionizing radiation. MRI on the other hand requires patient stability during the scan to eliminate image motion artifacts. For imaging cadaver specimens, CT was prefered over MRI since the latter requires the tissue to be wet.

Based on these considerations, in the second part of the study, CT scans were performed on the cadavers and the TC volumes were measured and compared against the benchmark histological findings. Multiple observers performed the measurements using an image processing software developed in house. The accuracy and reproducibility of the results were tested by characterizing and comparing the inter and intra observer performances. The reliability of the results were evaluated with the help of Dice and Jaccard similarity indices (Somasundaram \& Kalaiselvi, 2010, 2011; Kundel \& Polansky, 2003).

\section{MATERIAL AND METHOD}

The study was performed on 5 newborn cadavers after an approval by the Local Ethics Committee of Erciyes University, Kayseri, Turkey. The cadavers were fixed by carotid artery perfusion and preserved in a $10 \%$ formalin solution for 6 months.

Anthropometric measurements. The body height $(\mathrm{cm})$ and body weight $(\mathrm{g})$ of each newborn cadaver were measured by a trained examiner by following the standardized protocols. Body height was measured to the nearest $0.1 \mathrm{~cm}$ with an Iowa Height Board and body weight to the nearest $0.1 \mathrm{~kg}$ by using a balance beam metric scale. In addition, head length (HL), head width (HW), head height (HT) and head circumference (HC) were measured using a caliper, as described earlier (Acer et al., 2007). Maximum HL (glabellainion length: HL), maximum head breadth (between right and left eurions: HW), and maximum head height (between the external acoustic meatus and the highest point of the vertex: $\mathrm{HH}$ ) were recorded. The head circumference (HC) was obtained by placing a flexible measuring tape on the occipital protuberance behind and supraorbital ridge in front (Akhter et al., 2012).

CT Scans. The cadavers were placed in a supine position and then went through head scan using a CT scanner
(Toshiba Aquilion One, Medical Systems). Images were acquired sequentially in axial planes parallel to the orbitomeatal line. Multi-slice acquisition and reconstruction parameters were FOV of $18 \mathrm{~cm}$, rotation time of $1 \mathrm{sec}$, section thickness of $0.5 \mathrm{~mm}$ and reconstructed image matrix of 512 $\mathrm{x} 512$, pixel size of $0.12 \mathrm{~mm}$ x $0.12 \mathrm{~mm}$ while $\mathrm{kVP}$ was 120 and $\mathrm{mA}$ was 200. The images were stored in Dicom format. Figure 1 shows TC using one of the CT data sets after volume rendering in $3 \mathrm{D}$.

Histology. After the CT scans, temporal bones were dissected from the cadavers and decalcified in $5 \%$ nitric acid in formaldehyde. Each sample was then paraffin embedded by preserving its anatomical orientation same as in cadaver for enabling one-to-one comparison of the final histology sections with the corresponding $\mathrm{CT}$ images in axial direction. The blocks were subjected to $20 \mu \mathrm{m}$ thick axial sectioning at $0.2 \mathrm{~mm}$ intervals using a rotary microtome. The resulting slides were stained with hematoxylin-eosin (HE) and examined under a stereomicroscope (Carl Zeiss, Germany) with magnification at $5 x$. In the presence of a reference ruler, the slides were digitally photographed with high resolution camera ( 3 mega pixels) and saved in tiff format.

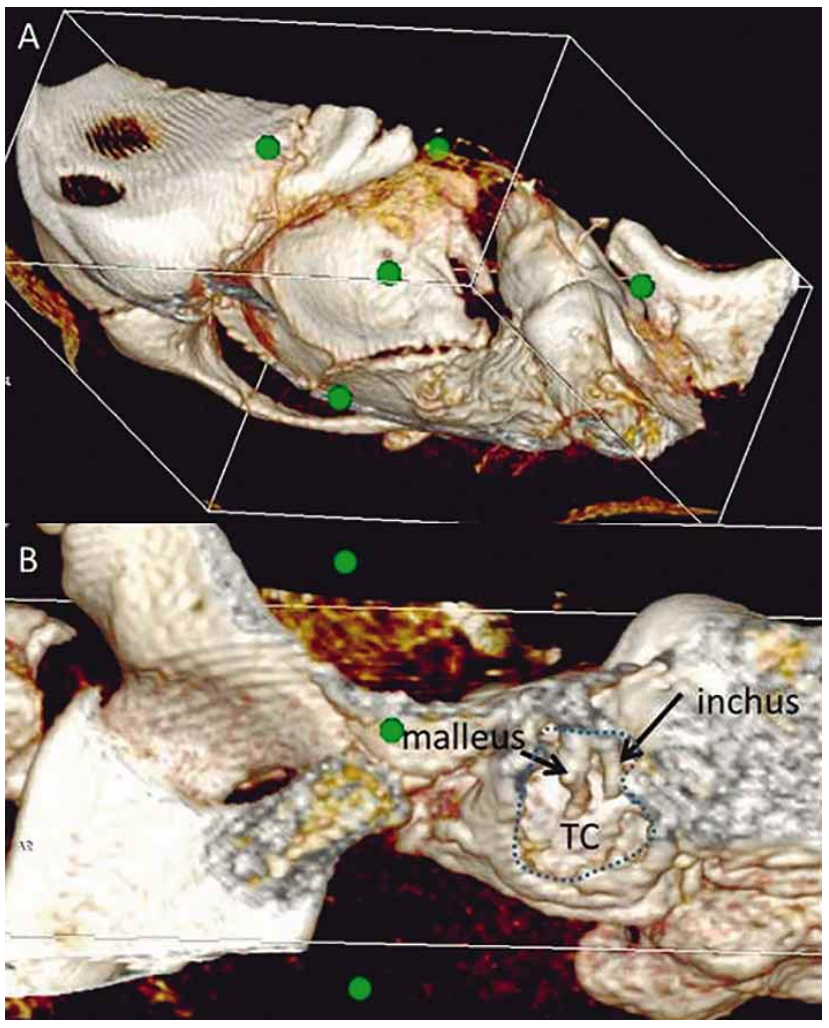

Fig. 1. Visualization of TC with 3D volume rendering of CT images. Top: Slightly superior view of the lateral skull base and Bottom: Lateral view of ossicular chain. Dotted line denotes the boundary of TC. 
TC volume estimation. The software ImageJ (http:// www.rsb.info.nih.gov/ij/download) was installed in a PC and used for estimating the TC volumes from both the histology and CT data. Region of interests (ROI) covering the inner lining of the TC were manually traced on images as shown in Fig. 2. The total volume of TC was calculated from the selected areas in the consecutive images using the formula:

$$
V_{T C}=t x P x \sum_{i=1}^{N} A_{i}
$$

Here, the coefficient $\mathrm{t}$ represents slice thickness in $\mathrm{mm}(\mathrm{t}=$ $0.22 \mathrm{~mm}$ for the histology data and $0.5 \mathrm{~mm}$ for the CT data), $\mathrm{P}$ denotes pixel area in $\mathrm{mm}^{2}$ and $\mathrm{Ai}$ represents the number of pixels in the selected region of image $\mathrm{i}$ out of total $\mathrm{N}$.

The TC tissue was hard and thus did not shrink or deform during the histological preparation or sectioning. The spatial resolution of the histology images was significantly higher than the CT images. Therefore, the errors made in estimating the volumes using histology data were substantially lower and the volume measurements would be closer to the real values. Thus, the histology based volume estimates were considered to be ground truth reference for benchmark comparison of the CT based estimates.

Accuracy, repeatabilty and reliability of the TC volume measurements. Accomplishing accuracy, repeatability and reliability analysis involved two anatomists, participating as assessors measuring the TC volumes. Each assessor independently and blindly outlined the TC on the CT images. The selected ROIs on the CT images were converted into binary masks and saved in bitmap format. Figure 3 presents the steps involved in masking out TC. The spatial domain of

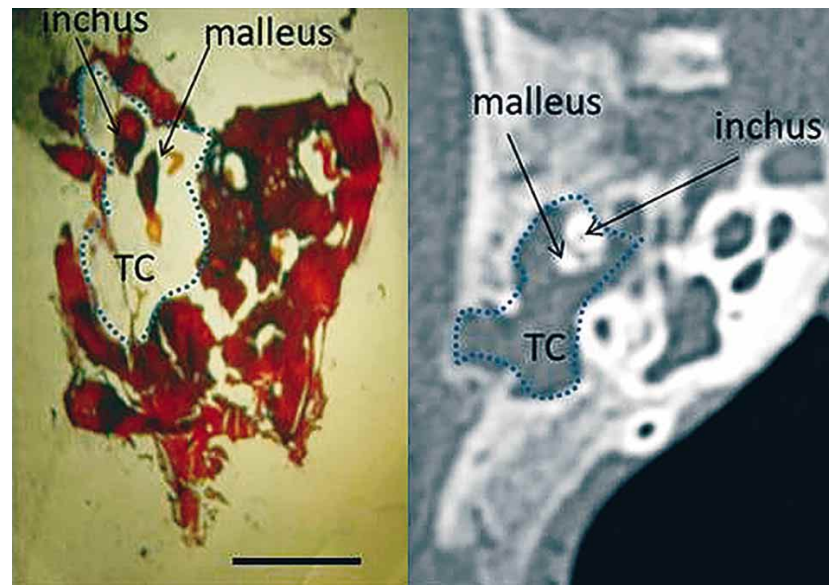

Fig. 2. Representative slides showing TC on histology (H\&E stained) and CT slices. Bar represents $500 \mu \mathrm{m}$ of length. The closed dottet lines denote the manually selected boundaries of TC, from which the area on the images and subsequently the volume of TC were estimated from the consequtive images collectively by taking the slice thickness into account. the masks collectively represented the total volume of TC in 3D. Next, the TC volume was calculated according to formula described above. Assessors repeated the measurements 3 days later. The results were tabulated for statistical analysis, as discussed below.

The accuracy of the TC volume measurements was determined by statistically comparing the volume readings against the histology-based measurements. The repeatabilty was determined by statistically evaluating the intra and inter assessor variabilities in the volume readings. Accurate and repeatable results necessitate consistency in the selected volumes and its limits are ultimately affected by the degree of agreement or disagreement between the volumes segmented out by the assessors. To explore this further, additional numerical analysis was performed to characterize the similarity of the selected volumes by the assessors, as a predictor of reliability. In the literature, several measures were reported for quantitatively comparing the structural similarities between the two data sets (Somasundaram \& Kalaiselvi, 2011). In this study, we employed Dice and Jaccard similarity indices (Dice, 1945; Jaccard, 1912), as they had the capacity to define the quality of spatial overlap between the two volumes. Given two volumetric data sets A and $\mathrm{B}$, the Dice and Jaccard Indices were calculated by

$$
\begin{aligned}
& \text { Dice }=2 \frac{|A \cap B|}{|A|+|B|} \\
& \text { Jaccard }=\frac{|A \cap B|}{|A \cup B|}
\end{aligned}
$$

Here $\cap$ denotes intersection and $\bigcup$ denotes union of the volumes and || denotes the volumetric size of the argument. According to the equations above, the indices range between 0 and 1 , where 0 represents no spatial match and 1 represents an excellent consistency or overlap between the selected two volumes. The calculations of the indices were carried out using a software developed in house under Matlab platform (version 2012a, MathWorks Inc., Natick, MA, USA).

Statistical Analysis. Overall, there were 10 TCs extracted from 5 cadavers. Thus, histology-based volume data included 10 measurements. Since, two assessors performed the CTbased volume measurements twice, the resulting data were separated into 4 groups, each with 10 measurements. The accuracy and repeatability of the CT-based volume measurements were characterized by calculating inter-class correlation coefficient between the histology-based volume data and the CT-based data in all 4 groups together. The reliability of the results was measured with Dice and Jaccard similarity indices as statistical validation metrics and involved comparing the performances of the assessors in their repeatitive or cross manual segmentations of the TC volume. 
ACER, N.; UNUR, E.; SÖNMEZ, M. F.; ZARARSIZ, G.; ARSLAN, A.; SAGIROGLU, A.; ERTEKIN, T.; ERKAN, M.; COSKUN, A. \& BILGEN, M. Characterization of tympanic cavity volume in newborns using computerized tomography scanning. Int. J. Morphol., 34(1):189-196, 2016.

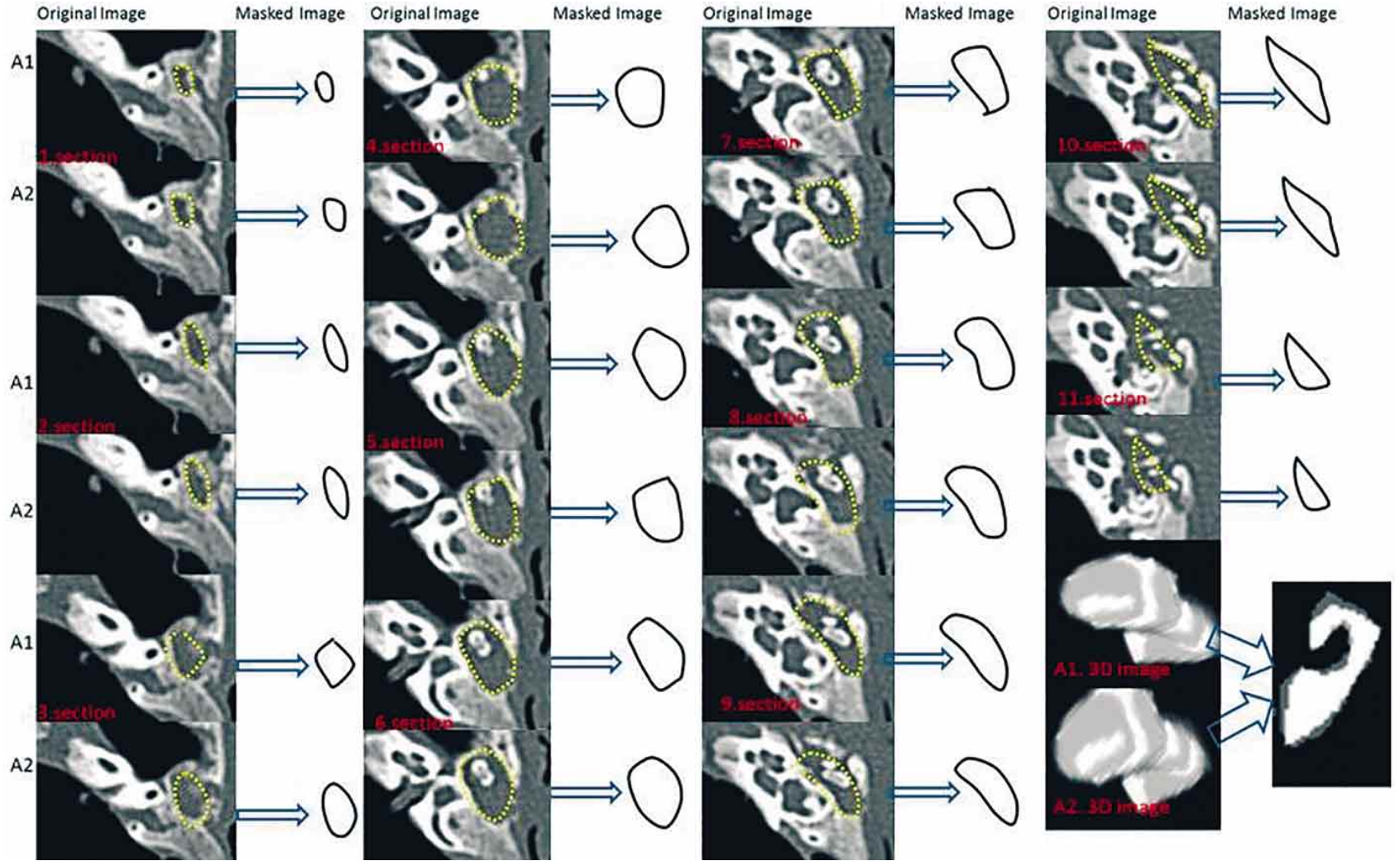

Fig. 3. Image processing steps employed for the analysis of inter and intra assessor performances using Dice and Jaccard similarity measures. A1:Assessor 1, A2: Assessor 2.

\section{RESULTS}

The physical parameters measured from the cadaver head specimens were described in Table I. The measurements of TC volumes based on the analysis of histology and CT data were listed in Table II. Spearman's correlation coefficient between the histology-based TC volumes and $\mathrm{HC}, \mathrm{HL}$, and $\mathrm{HC}$ values were positive and significant (>0.9). TC volumes measured from the right and left sides were not significantly different statistically $(\mathrm{P}>0.001)$.
The TC volume assessed from the CT data second time around by both assessors appeared to be closer to the real values on the average (Fig. 4). This trend suggested assessor's ability in correctly identifying and segmenting out the TC improves with repetition or training on the same subject. However, intraclass correlation analysis performed to test the accuracy of the measurements yielded mixed results (Data in accuracy column of Table III). With repetition, the level of correlation increased for the Assessor 1, but decreased for the Assessor 2.

Table I. The anthropometric parameters of the newborns; body weights, heights and head dimensions.

Body weight (g)

Body height $(\mathrm{cm})$

Head circumference (cm, HC)

Head width (cm, HW)

Head height $(\mathrm{cm}, \mathrm{HH})$

Head length (cm, HL)

\begin{tabular}{cccc} 
Minimum & Maximum & Mean & SD \\
\hline 1100 & 3400 & 2220 & 1056.88 \\
37 & 57.8 & 46.68 & 8.78 \\
27 & 34 & 31 & 3.17 \\
6.9 & 8.9 & 7.78 & 0.87 \\
5.4 & 10.5 & 7.78 & 1.86 \\
8.9 & 13.6 & 11.22 & 1.75
\end{tabular}


Table II. Measurements of TC Volumes based on the histology and CT data. CT based measurements were performed independently and blindly by two assessors (A1 and A2) at 2 different days (M1 and M2) of 3 days apart.

\begin{tabular}{lcccc}
\hline \multirow{2}{*}{$\begin{array}{l}\text { Histology } \\
\left(\mathrm{mm}^{3}\right)\end{array}$} & \multicolumn{2}{c}{ Assessor 1 (A1) } & \multicolumn{2}{c}{ Assessor 2 (A2) } \\
\cline { 2 - 5 } & $\begin{array}{c}\text { Measurement 1 } \\
\text { (M1) }\end{array}$ & $\begin{array}{c}\text { Measurement 2 } \\
\text { (M2) }\end{array}$ & $\begin{array}{c}\text { Measurement 1 } \\
\text { (M1) }\end{array}$ & $\begin{array}{c}\text { Measurement 2 } \\
\text { (M2) }\end{array}$ \\
\hline 380 & 416 & 404 & 347 & 310 \\
340 & 440 & 369 & 382 & 355 \\
185 & 273 & 177 & 178 & 151 \\
155 & 156 & 183 & 149 & 160 \\
230 & 302 & 274 & 238 & 255 \\
256 & 333 & 268 & 289 & 256 \\
228 & 260 & 280 & 216 & 226 \\
214 & 254 & 255 & 235 & 222 \\
311 & 285 & 283 & 319 & 300 \\
319 & 367 & 372 & 342 & 351 \\
\hline
\end{tabular}

Table III. Observer performances as evaluated by intra-class correlation coefficients computed between the histology and CT based TC volume measurements.

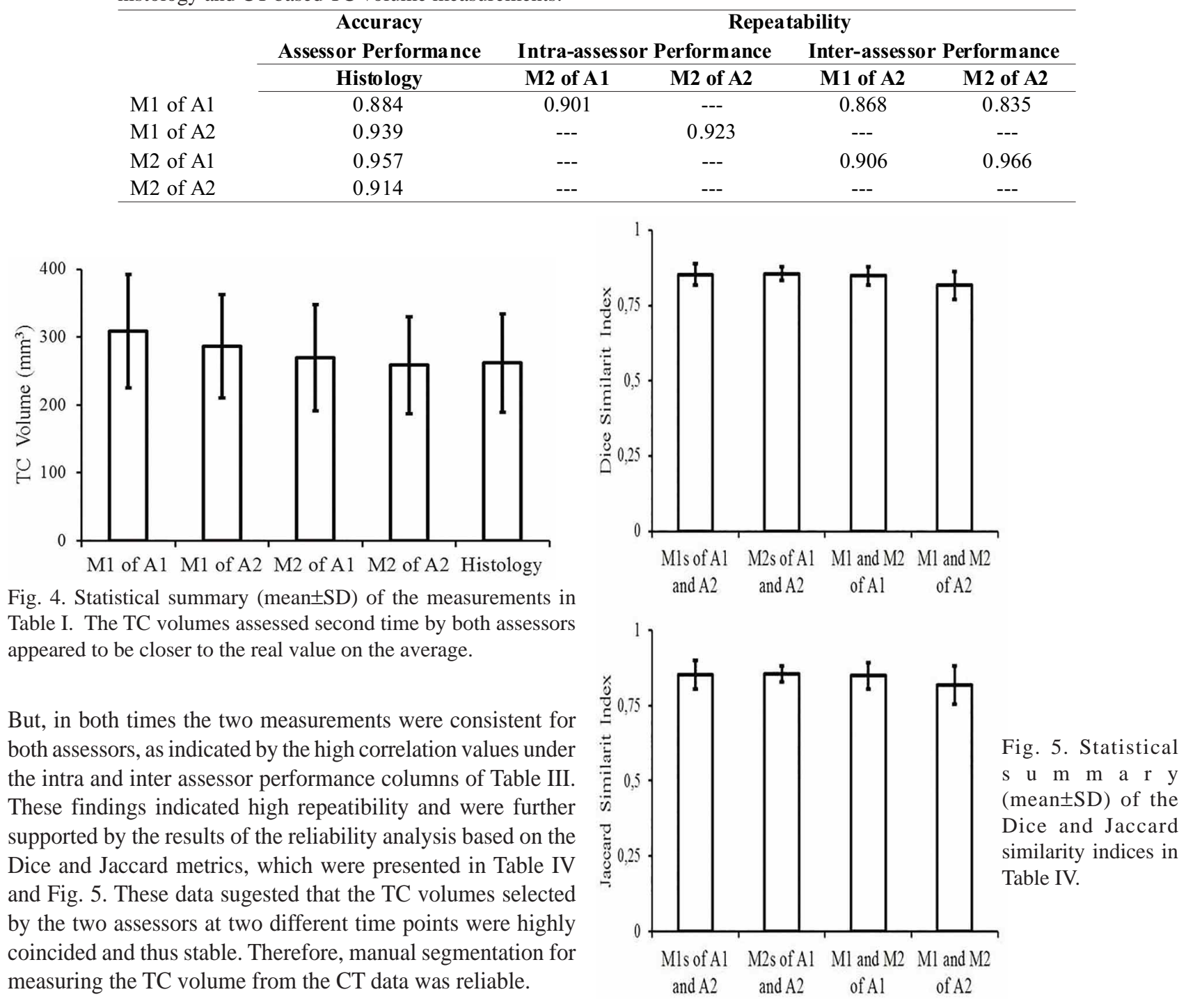


Table IV. Results of Dice and Jaccard similarity indices computed from the volumes segmented manually by two assessors on 2 different days.

\begin{tabular}{cccccccc}
\hline \multicolumn{2}{l}{ M1s of A1 and A2 } & \multicolumn{2}{c}{ M2s of A1 and A2 } & \multicolumn{2}{c}{ M1 and M2 of A1 } & \multicolumn{2}{c}{ M1 and M2 of A1 } \\
\hline Dice & Jaccard & Dice & Jaccard & Dice & Jaccard & Dice & Jaccard \\
\hline 0.86 & 0.75 & 0.88 & 0.77 & 0.84 & 0.72 & 0.86 & 0.75 \\
0.87 & 0.78 & 0.87 & 0.74 & 0.83 & 0.71 & 0.74 & 0.59 \\
0.88 & 0.78 & 0.88 & 0.77 & 0.87 & 0.77 & 0.86 & 0.75 \\
0.77 & 0.63 & 0.85 & 0.74 & 0.89 & 0.8 & 0.74 & 0.59 \\
0.87 & 0.77 & 0.85 & 0.73 & 0.87 & 0.77 & 0.84 & 0.72 \\
0.86 & 0.76 & 0.83 & 0.71 & 0.82 & 0.7 & 0.81 & 0.68 \\
0.83 & 0.73 & 0.86 & 0.74 & 0.82 & 0.7 & 0.83 & 0.72 \\
0.89 & 0.76 & 0.81 & 0.7 & 0.87 & 0.76 & 0.81 & 0.7 \\
0.87 & 0.78 & 0.87 & 0.77 & 0.87 & 0.78 & 0.87 & 0.77 \\
0.82 & 0.7 & 0.85 & 0.77 & 0.8 & 0.67 & 0.81 & 0.68 \\
\hline
\end{tabular}

\section{DISCUSSION}

In the literature, traditional serial histological sectioning has often been used for volumetric sizing, including middle and inner ear (Decraemer et al., 2002; Rau et al., 2013; Wang et al., 2006; Sun et al., 2002). This approach provides the greatest detail but is very time consuming. Being an ex-vivo procedure also makes it not applicable for in vivo assessment of TC, as required in clinics. Nevertheless, we included histology-based measurement of $\mathrm{TC}$ volume as a reference comparison. Errors in this approach originated from shrinkage, tearing and folding of the tissue sections (Sun et al.). These effects were minimized by performing the histology preparation and analysis of the samples right after the CT scans. In this study, we followed this approach and visual evaluation indicated that the shrinkage of temporal bone was negligible in the analyzed samples. However, accroding to the data in Table II, reference measurements appeared to be slightly lower, which may be due to the variations in clearly delinating especially the lower and upper borders of the $\mathrm{TC}$ as well as the measurement volume being small.

In vivo examination of temporal bone is possible with the current imaging equipment used in clinical radiology. Within all, multi slice CT scanner provides the best quality and high resolution images, necessary for visualizing and differenting bony structures including TC (Rau et al.). Given its relatively small size, we opted imaging TC with CT in newborn cadavers. CT-based volumetric measurement depends on the complexity of anatomy and quality of the scans, as well as performance of the assessor. The acquired data however allowed measuring the TC size accurately and repetitively (Table II), which indicated that CT is a wellsuited imaging modality for this purpose. Dice and Jaccard similarity values in Table IV and plots in Figure 5 implied minimal differences between the ROI markings between the assessors, meaning that the selected traces of the TC boundary were in very close proximity. This provided additional evidence on the validity and applicability of our image processing protocol and selection criterions for segmenting TC. Our findings based on the Dice and Jaccard analysis were in agrement with those of the previous studies who sized other body organs or anatomical structures (Chang et al., 2009; Duda et al., 2001; Lee et al., 2003; La Macchia et al., 2012).

Previously, TC size in adults has been studied and found to range from 500 to $1000 \mathrm{~mm}^{3}$ (Werner et al., 2011; Whittemore et al., 1998). However, only few studies reported TC size in newborns and no study has investigated the relationsip between the TC volume and head dimensions. In a study with 14 normal humans; 6 infants who were under 1 year of age and 8 adults, Ikui et al. reported TC size in adults as $640.1 \pm 69.1 \mathrm{~mm}^{3}$ which was about 1.5 times larger than that of the infants $451.7 \pm 68.2 \mathrm{~mm}^{3}$. In a 22 day old infant, $\mathrm{TC}$ volume was reported as $330 \mathrm{~mm}^{3}$. In the current study, the TC volume in newborns was found to range between 155 and $380 \mathrm{~mm}^{3}$ when measured with the histological analysis (Table I). In addition, TC size has increased with increase in head circumference. This was in agreement with a previous report which indicated that the TC size increases in proportion to pneumatization in bone surrounding the cavity (Ikui et al.).

Ahn et al. (2008), found that chronic otitis media causes reduced middle ear volume compared to those contralateral normal ears. A smaller middle-ear cavity 
increases the stiffness of the middle-ear at ear-canal just in front of the tympanic membrane, because the membrane motion drives against the volume compliance (Werner $e t$ al.). Whether it is an anatomical abnormality or postnatal origin, the change in TC size may have clinical implications for surgical and medical treatment planning, but its accurate measurement can be more critical for the prior diagnostics.

One of the limitations of this study was the small sample size. Finding newborn cadavers is a common problem faced in many anatomy departments. Analysis based on the availability of more cadavers would further strengthen the findings presented above. The other limitation was the manual segmentation of TC. Automation would speed up the evaluation process. But this would require using computer-aided artificial intelligence to identify the lower section of the TC axial limit, which often requires expert judgement or involvement because of insufficient tissue contrast to make the required distiction. From clinical perspective, our image acquisition protocol may not be appropriate since CT scans on children are avoided to limit the radiation exposure.

An interesting future project would be to study the potential of the method to automatically and objectively discriminate the black and white areas within the identified cochlea region using contrast differences in CT images. Taking into account these limitations, this is the first newborn postmortem study to provide quantitative evidence. We will continue our research on more accurate and efficient to calculate other anatomical structures. This work demonstrates that the presented method fills the gap between the basic biological research relying on postmortem histologic material and clinical applications relying on in-vivo CT-based image analysis. The measurement of TC volume in newborn cadavers is feasible with high resolution CT data. Volume computations from simple slice-by-slice manual segmentation of the TC boundary provide accurate, reproducible and reliable results provided the assessors are expert anatomists or the selection criteria is well defined prior to starting the segmentation process. Correlations exist among the TC volume and head circumference and head length, which may offer value in disease diagnosis and treatment or surgical intervention. The Dice and Jaccard values are simple and useful measures of spatial overlap, which can be applied to studies of accuracy and reproducibility in image comparison. The developed software can potentially be applied to measure other anatomical volumes from radiological images.

\section{ACKNOWLEDGMENTS}

We wish to thank Kenan Aycan, Prof. Dr.; Harun Ulger, Prof. Dr. for skillful technical assistance. This study was supported the Scientific Research divison of Erciyes Universty, Kayseri, Turkey (Project no: TAO-11-3618).

ACER, N.; UNUR, E.; SÖNMEZ, M. F.; ZARARSIZ, G.; ARSLAN, A.; SAGIROGLU, A.; ERTEKIN, T.; ERKAN, M.; COSKUN, A. \& BILGEN, M. Caracterización del volumen de la cavidad timpánica en recién nacidos usando tomografía computadorizada. Int. J. Morphol., 34(1):189-196, 2016.

RESUMEN: El objetivo fue determinar el volumen de la cavidad timpánica (CT) en recién nacidos, información no encontrada en la literatura. Se realizaron escaners a través de tomografia computadorizada (TC) y estudios histológicos en el hueso temporal; los datos se analizaron utilizando un software desarrollado en nuestra institución. Se obtuvieron imágenes de secciones de TC, de $0,5 \mathrm{~mm}$ de grosor, a partir de 5 cadáveres de recién nacidos, los que fueron analizados de forma independiente por dos investigadores expertos. El margen de los cortes de TC fue delineado manualmente y la medición del área de interés se estimó sobre imágenes ocultas. Después, se añadieron las mediciones de área de todas las secciones para estimar el volumen total. Las concordancias entre el estudio histológico y los hallazgos de la TC se compararon en cuanto a precisión, repetibilidad y confiabilidad. Se utilizaron las medidas de coeficiente de similitud de Jaccard y Dice como métrica de validación estadística para evaluar el desempeño del asesor en la medición manual del volumen. Se observó una buena correlación del evaluador con los valores medios de Dice, por encima de 0,8 indicando que es factible obtener mediciones coherentes y confiables de volumen. El protocolo propuesto ha demostrado ser preciso para calcular el volumen de la CT, y por lo tanto se puede utilizar para la planificación prequirúrgica asistida o para el diagnóstico de alteraciones estructurales en la CT.

PALABRAS CLAVE: Tomografía computadorizada; Cavidad timpánica; Volumen de cavidad timpánica; Índice de similitud. 
ACER, N.; UNUR, E.; SÖNMEZ, M. F.; ZARARSIZ, G.; ARSLAN, A.; SAGIROGLU, A.; ERTEKIN, T.; ERKAN, M.; COSKUN, A. \& BILGEN, M. Characterization of tympanic cavity volume in newborns using computerized tomography scanning. Int. J. Morphol., 34(1):189-196, 2016.

\section{REFERENCES}

Acer, N.; Usanmaz, M.; Tugay, U. \& Ertekin, T. Estimation of cranial capacity in 17-26 years old university students. Int. $J$. Morphol., 25(1):65-70, 2007.

Ahn, J. Y.; Park, H. J.; Park, G. H.; Jeong, Y. S.; Kwak, H. B.; Lee, Y. J.; Shin, J. E. \& Moon, W. J. Tympanometry and CT measurement of middle ear volumes in patients with unilateral chronic otitis media. Clin. Exp. Otorhinolaryngol., 1(3):13942, 2008.

Akhter, Z.; Banu, L. A.; Alam, M. M. \& Rahman, M. F. Stature estimation from craniofacial anthropometry in Bangladeshi Garo adult females. Mymensingh Med. J., 21(3):479-84, 2012.

Chang, H. H.; Zhuang, A. H.; Valentino, D. J. \& Chu, W. C. Performance measure characterization for evaluating neuroimage segmentation algorithms. Neuroimage, 47(1):122-35, 2009.

Decraemer, W. F.; Khanna, S. M. \& Dirckx, J. J. J. The integration of detailed 3D anatomical data for the quantitative description of 3D vibration of a biological structure: an illustration from the middle ear. Proc. SPIE, Fifth International Conference on Vibration Measurements by Laser Techniques: Advances and Applications, 4827:148-58, 2002.

Dice, L. R. Measures of the amount of ecologic association between species. Ecology, 26(3):297-302, 1945.

Duda, R. O.; Hart, P. E. \& Stork, D. G. Pattern Classification. $2^{\text {nd }}$ ed. New York, John Wiley \& Sons, 2001.

Ikui, A.; Sando, I.; Haginomori, S. \& Sudo, M. Postnatal development of the tympanic cavity: a computer-aided reconstruction and measurement study. Acta Otolaryngol., 120(3):375-9, 2000.

Jaccard, P. The distributoon of the flora in the alpine zone. New Phytol., 11(2):37-50, 1912.

Kavakli, A.; Ogeturk, M.; Yildirim, H.; Karakas, S.; Karlidag, T. \& Sarsilmaz, M. Volume assessment of age-related conversion of the tympanic cavity by helical computerized tomography scanning. Saudi Med. J., 25(10):1378-81, 2004.

Kundel, H. L. \& Polansky, M. Measurement of observer agreement. Radiology, 228(2):303-8, 2003.

Kürkçüoglu, A.; Kürkçüoglu, S. S.; Inançli, H. M.; Enöz, M.; Pelin, C. \& Zagyapan, R. Measurement of tympanic cavity volume by the Cavalieri principle in Turkish population. Kulak Burun Bogaz Ihtis Derg, 20(3):137-41, 2010.

La Macchia, M.; Fellin, F.; Amichetti, M.; Cianchetti, M.; Gianolini, S.; Paola, V.; Lomax, A. J. \& Widesott, L. Systematic evaluation of three different commercial software solutions for automatic segmentation for adaptive therapy in head-and-neck, prostate and pleural cancer. Radiat. Oncol., 7:160, 2012.

Lee, J. M.; Yoon, U.; Nam, S. H.; Kim, J. H.; Kim, I. Y. \& Kim, S. I. Evaluation of automated and semi-automated skull-stripping algorithms using similarity index and segmentation error. Comput. Biol. Med., 33(6):495-507, 2003.

Mehta, R. P.; Rosowski, J. J.; Voss, S. E.; O'Neil, E. \& Merchant, S. N. Determinants of hearing loss in perforations of the tympanic membrane. Otol. Neurotol., 27(2):136-43, 2006.

Rau, T. S.; Würfel, W.; Lenarz, T. \& Majdani, O. Three-dimensional histological specimen preparation for accurate imaging and spatial reconstruction of the middle and inner ear. Int. $J$. Comput. Assist. Radiol. Surg., 8(4):481-509, 2013.

Somasundaram, K. \& Kalaiselvi, T. Brain extraction method for T1-weighted magnetic resonance scans. Bangalore, IEEE Signal Processing and Communications (SPCOM), 2010 International Conference, 2010. pp.1-5.

Somasundaram, K. \& Kalaiselvi, T. Automatic brain extraction methods for $\mathrm{T} 1$ magnetic resonance images using region labeling and morphological operations. Comput. Biol. Med., 41(8):716-25, 2011.

Standring, S. Gray's Anatomy: The Anatomical Basis of Clinical Practice. London, Churchill Livingstone, 2008.

Sun, Q.; Chang, K. H.; Dormer, K. J.; Dyer, R. K. Jr. \& Gan, R. Z. An advanced computer-aided geometric modeling and fabrication method for human middle ear. Med. Eng. Phys., 24(9):595-606, 2002.

Wang, H.; Northrop, C.; Burgess, B.; Liberman, M. C. \& Merchant, S. N. Three-dimensional virtual model of the human temporal bone: a stand-alone, downloadable teaching tool. Otol. Neurotol., 27(4):452-7, 2006.

Werner, L. A.; Popper, A. N. \& Fay, R. R. Human Auditory Development. New York, Springer, 2011.

Whittemore, K. R. Jr.; Merchant, S. N. \& Rosowski, J. J. Acoustic mechanisms: canal wall-up versus canal wall-down mastoidectomy. Otolaryngol. Head Neck Surg., 118(6):75161, 1998.
Correspondence to:
Assoc. Prof.Niyazi Acer
Erciyes University
Medical Faculty
Department of Anatomy
38039 Kayseri
TURKEY

Email: nacer@erciyes.edu.tr 